\title{
Spontaneous rupture of the uterus associated with pyometra
}

\author{
Derek J. Parkinson* and Brian Alderman \\ Department of Obstetrics and Gynaecology, Arrowe Park Hospital, Wirral, UK
}

\begin{abstract}
Summary: A case is reported in which an elderly patient was admitted with signs and symptoms of an acute abdomen. A laparotomy revealed uterine rupture with free pus in the peritoneal cavity and subsequent histology of the uterus showed no evidence of malignancy.
\end{abstract}

\section{Introduction}

Spontaneous rupture of the uterus is rare, but may occur following the formation of a pyometra. However, this is usually associated with development of an underlying uterine malignancy. In our case there was no associated malignancy and the cause of the rupture remains obscure.

\section{Case report}

A 78 year old nulliparous unmarried woman was admitted to hospital as an emergency to the surgical unit with a short history of central abdominal pain of sudden onset associated with nausea and vomiting. For several months she had experienced frequency of micturition but no dysuria. The menopause had occurred at the age of 50 years. She denied any postmenopausal bleeding or vaginal discharge but she had suffered from rheumatoid arthritis and for several years had been taking indomethacin $25 \mathrm{mg}$ and prednisolone $2.5 \mathrm{mg}$ both twice daily.

On examination her abdomen showed board-like rigidity and was markedly tender. It was not distended but bowel sounds were absent. Rectal examination revealed soft faeces but vaginal examination was not performed. Haemoglobin and white cell count were unremarkable; an erect abdominal X-ray revealed no free sub-diaphragmatic gas.

Laparotomy was performed and $200 \mathrm{ml}$ of pus was found in the peritoneal cavity. A small perforation approximately $5 \mathrm{~mm}$ long was found in the uterine fundus. The uterus itself was small and atrophic but

Derek J. Parkinson, M.B., Ch.B., M.R.C.O.G. and Brian Alderman, M.B., Ch.B, F.R.C.O.G.

*Present address: Department of Obstetrics and Gynaecology, Welsh National School of Medicine, Heath Park, Cardiff, CF44XN.

Accepted: 2 November 1983 otherwise appeared normal. Total hysterectomy and bilateral salpingo-oophorectomy were performed and a corrugated drain inserted through the vaginal vault which was left partially open. Her convalescence was uneventful.

Histological sections of the uterus revealed a pyometra with mural inflammation and destruction of the endometrium. They showed no evidence of malignancy. Both ovaries were histologically normal.

\section{Discussion}

Pyometra is common in post-menopausal women and is usually asymptomatic (Whiteley \& Hamblett, 1971). It is a frequent incidental finding during post-mortem examinations. In most cases the pyometra drains intermittently via the cervix which is likely to be the path of least resistance. Spontaneous rupture of the uterus allowing drainage of the pyometra into the abdominal cavity is rare but when it occurs it is commonly associated with malignancy involving the myometrium. A small number of cases have been reported where rupture occurred at the site of myomata which became infected (Lister, 1959; Miller, 1945; Olszewski \& Waegler, 1971). In another case there was necrosis of the myometrium at the site of the rupture (Loup, 1973). Histological examination of the uterus in our case revealed no evidence of malignancy, myomata or other abnormality adjacent to the site of the rupture, and therefore no obvious predisposing factor to account for the spontaneous rupture of the uterus.

Long term steroid therapy would however have predisposed her to infection which may have caused the tissues to become more friable as the infection invaded the myometrium It is also possible that the uterus may have been previously perforated during dilatation and curettage which may have been performed at the time of an earlier vaginal repair operation. 
The cause of this rupture is uncertain and one can only postulate that the cervix was so tightly stenosed

\section{References}

LISTER, U.M. (1959). Spontaneous perforation of the uterus. Journal of Obstetrics and Gynaecology of the British Empire, 66, 988.

LOUP, J. (1973). Spontaneous uterine perforation due to pyometra with necrosis. Journal de Chirurgie (Paris), 105, 303.

MILLER, I. (1945). Suppurating fibro-myomas - report of a case with review of the literature. American Journal of Obstetrics and Gynecology, 50, 522. that it provided a greater resistance to the outflow of pus than did the myometrium itself.

OLSZEWSKI, Z. \& WAEGLER, C. (1971). Asymptomatic spontaneous uterine perforation at the site of a partiallyo necrotized myoma showing a tendency for restitution $\bar{\omega}$ Polski Tygodnik Lekarski (Warsaw), 26, 1322.

WHITELEY, P.F. \& HAMBLETT, J.D. (1971). Pyometra - a reappraisal. American Journal of Obstetrics and Gyn-w ecology, 109, 108. 